\title{
A Study on the Factors Influencing Green Warehouse Practice
}

\author{
Lew Jia Xin ${ }^{1}$, Kang Ching Xien ${ }^{1}$, and Siti Norida Wahab ${ }^{1 *}$ \\ ${ }^{1}$ Faculty of Business and Information Science, UCSI University, Jalan Menara Gading, 56000 Cheras, Kuala Lumpur, Malaysia
}

\begin{abstract}
Going green in logistics business operation has been the main initiatives to reduce the carbon footprint while generating profit. This study described about the green practice and the drivers in the Malaysia warehousing industry. The purpose of the study is to investigate the factors of adopting green warehousing $(\mathrm{GWH})$ with the main aim of exploring current green warehouse practice (GHP) in Malaysia and the factors affecting them. The relationship between government engagement, customer, supplier, manager, employee's engagement, technology innovation and green warehouse practice has been analyzed. Data was gathered by survey methods. The survey was established for warehouse's employees with superior or managerial position based in Malaysia. Quantitative methods used to emphasize the objective measurements and to identify how closed the relationship are. Data were analyzed using SPSS software in terms of inferential analysis. The key findings showed that the independent variables had a strong and significant relationship with the GWP.
\end{abstract}

\section{INTRODUCTION}

The concept of going green in the logistics and supply chain has a directly impact on the operation of the conventional warehouse as they should be transformed into a greener operation of with the environmental concern. Besides, the researchers see the green logistics as part of the component in the green supply chain practice [1]. The green logistics is including few different processes and one of them is green warehousing [2]. According to Laari et al. [3], green supply chain and logistics minimized the environmental impact by dealing with every possible activities involved, the one of these is warehousing. Plus, practicing the greener warehouse operation, it helps to protect the environment ethically and comply with reduction cost of operation in long run [3]. Thus, the optimization of warehouse practices toward environmental friendly might be seen to improve the efficiency as well as competitiveness of company [4].

According to the Amjed et al. [5], warehouse was referred as a distribution centre where a specific location, a building or a logistics service centre which used for storing goods from inbound and for outbound as well as used for many other functions ranging from distribution and composite storage. Warehouses are normally handling not only storage yet provided various types of value added services depend on the operation of the warehouse for example, special customization services. It has a critical function in both logistics and supply chain as it contributed $24 \%$ on the cost of logistics [6]. The contribution of $\mathrm{CO} 2$ in the warehousing industry should be concerned and taken into account to reduce the footprint as concerned about the environmental issues [7].
Piecyk et al. [8] argued that environmental practice in warehousing did help in carbon footprint reduction while minimizing the operating cost and increased the social responsibility.

Furthermore, an analysis was conducted through the life cycle analysis (LCA) based on this issues. The results mentioned the energy consumption from a warehouse was from the heating, ventilation and air conditioning (HVAC) which regarding to the operation of equipment and facilities [5].

Based on the research from Rao [9], the warehousing activity played vitally important roles in between the inbound and outbound logistics which gave a significant role and function of the warehouse. There were bunch of research and studies on the green supply chain management (GSCM) which involved various logistics activities to comply with greening ideas [10-12]. From the previous research of the scholar in Chen, Chang, \& $\mathrm{Wu}$ [13] discussed the important of the green ideas and innovation as well the origins. They mentioned that the green idea in the particular industry was the environmental trend for the firm to get the attention from the public to gain the competitive advantages.

An efficient supplier selection process is also important in order to be able to implement green warehousing practices. Ahi et al.[14] discussed an organization to practicing sustainable or green warehousing, the eight major elements should be considered, which are warehouse facility design, warehouse layout, inventory management, warehouse staff, warehouse operation, onsite facilities, warehouse management system and mechanical handling equipment (MHE) [14].

\footnotetext{
*Corresponding author's e-mail: sitinorida@ucsiuniversity.edu.my
} 
When looking into environmental-friendly approach, reduce, reuse and recycle (3R) is one of the undeniable practices that should be implemented in the operation. As an important component in green logistics and green supply chain, the activities happening were measured and redesign according to the environment compliance which reduce energy consumption and reduce the use of materials [15]. In addition, 3R concept pointed another matter concerned, wastage of packing is significant in the warehousing as many packaging process would be going through in the warehouse for an instance re-packaging for promotion items [16]. IT application was perceived as new idea and adoption for the organization to manage the operation activities that raging from the planning, controlling the transportation procedure to the storage function from the origin to the destination [17].

The present academic literature identifies GWH adoption affected by warehouse organization as well the external forces exerted on the organization $[18,19]$. The internal forces within the warehouse are manager and employees where external forces are government, supplier and customers. Nevertheless, there was no much research that discussed the green warehousing adoption and implementation. This research paper would test the significant relationship between the internal force, external force and information technology by using hypotheses testing method where the initiative taken would be identify as well.

Therefore, an empirical study of the factors determined that influence on the implementation of green warehousing was done. In this work, the factors of adopting green warehousing $(\mathrm{GWH})$ with the main aim of exploring current green warehouse practice (GHP) in Malaysia and the factors affecting them was carried out. This research paper would test the significant relationship between the internal force, external force and information technology by using hypotheses testing method where the initiative taken would be identify as well.

\section{METHODOLOGY}

\subsection{Research Design}

The objective of this study was to investigate the relationship between the GWH adoption and the stakeholders involved (manager, employee, government, supplier and customers) and information technology (IT).
The adoption of GWH was identified based on the green initiatives of warehousing industry regarding to the efficiency in Malaysia. In this paper, the quantitative method was used. This method was commonly used to determine the relationship mathematically between the independent variable (IV) and dependent variable (DV) [20, 21]

The survey was established for warehouse's employees with superior or managerial position based in Malaysia in order to clarify the green initiatives or practices that implemented in their warehouse. The researchers wanted to investigate the awareness level in this industry as it was still a new concept and idea for Malaysia-based organization. Warehouse managers and superior position holders considered as internal stakeholders were chosen as the participants in the survey because of their knowledge and experiences.

\subsection{Hypothesis}

This paper was developed and adapted from the theories from Ayuso et al. [22] as shown in Figure 1 where to discuss the green warehouse practice in Malaysia that initiated and were driven by both internal and external pressure. The (1) government, (2) customer (3) engagement of supplier, (4) manager, (5) employee and (6) technology innovation in logistics industry were used in this study as the Independent Variables (IVs) with the relationship of the green warehouse practice, the Dependent Variable (DV). The hypothesis under study is stated as follow. Ho1: There is no relationship between governments and green warehouse practice H11: There is relationship between governments and green warehouse practice. Ho2: There is no relationship between customer and green warehouse practice.H12: There is relationship between customer and green warehouse practice. Ho3: There is no relationship between suppliers and green warehouse practice. H13: There is relationship between supplier and green warehouse practice. Ho4: There is no relationship between manager and green warehouse practice. H14: There is relationship between manager and green warehouse practice. Ho5: There is no relationship between employees and green warehouse practice. H15: There is relationship between employees and green warehouse practice. Ho6: There is no relationship between technology innovations and green warehouse practice. H16: There is relationship between technology innovations and green warehouse practice. 


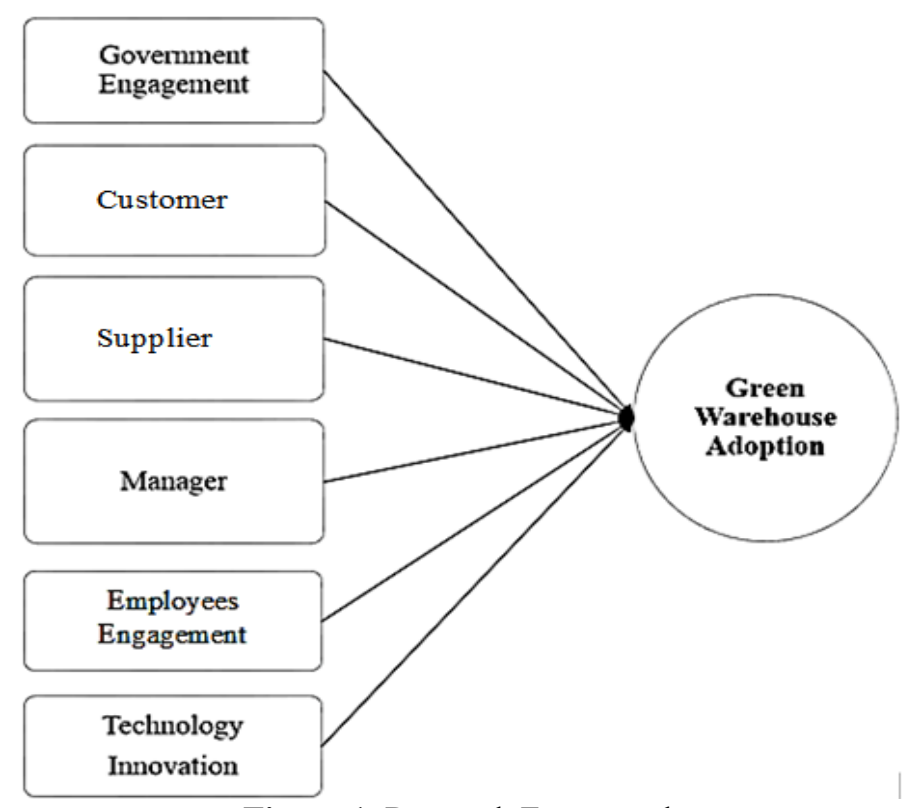

Figure 1. Research Framework

\subsection{Survey Development}

In this study, the questionnaire was designed in the form of closed-ended questionnaire or fixed-alternative question. These types of questions were ideal for calculating the statistical and mathematical data as the answers set were known. The questions were formed by using the existing literatures on green warehousing. Adaption from the survey was mainly assembled from presenting literature which was [19].

\subsection{Data collection}

In this research paper, internet databases and Google were used to find phone numbers to call the warehouse personnel and asked to take an online survey within their organization. An online version of the survey was advanced using a general survey software application. The researcher designed and created Google Form for the respondents and sent it to the chosen organizations. Online design provided benefits which including the control of answer orders, required completion of answers, response-dependent question pop-up or skipping capabilities and question format diversity.

\subsection{Data analysis}

Quantitative data from the survey was analyzed by SPSS and the results were analyzed as the descriptive statistics and inferential statistics (hypotheses testing). Validity and reliability is very important for a quantitative research. It gave the extent to which the study was accurately measured and valid $[23,24]$. Thus Reliability and normality test were done before the descriptive tests and inferential tests. All of the survey responses are kept and retrieved from the database, then restructured for simplicity of analysis by using quantitative techniques.. For hypotheses testing, the data was tested by using SPSS systems. The tests included are Correlation Analysis, ANOVA analysis and Multiple Regression.

\section{RESULT AND DISCUSSION}

The data analysis and tests in this section were all from the real sample that the researchers researched on. It consist reliability and normality tests, Pearson Correlation Coefficient Test, Multiple Linear Regression Analysis and Analysis of Variances (ANOVA).

\subsection{Reliability Test}

Table 1 shows the summary of the reliability test. From Table 1, it is observed that the reliability of this study was determined by the Cronbach's alpha. From the table above, all the variables had a Cronbach's value of 0.7 and above. It considered these variables were consistent and reliable. Thus, it could prove that the questionnaire was usable.

Table 1. Reliability Test for Dependent Variables and Independent Variables on final test result

\begin{tabular}{cc}
\hline Factors & Cronbach's Alpha \\
\hline Understanding GWH Implementation & 0.834 \\
IV- Government Factor & 0.847 \\
IV-Customer Factor & 0.730 \\
IV-Supplier Factor & 0.828 \\
IV-Manager Factor & 0.846 \\
IV-Employee Factor & 0.848 \\
\hline
\end{tabular}




$\begin{array}{cc}\text { IV-Technology Innovations Factor } & 0.868 \\ \text { DV-The current GWP } & 0.856 \\ \text { Overall } & 0.832\end{array}$

\subsection{Normality Test}

Table 2 shows the summary of the normality test. From Table 2, it is observed that the skewness and kurtosis value of government factor is 0.018 and 0.167 . The skewness and kurtosis value of customer factor is -0.355 and -0.876 . Besides, the skewness and kurtosis value of supplier factor is 0.142 and -0.682 . Then, the skewness and kurtosis value of manager factor is -0.029 and -0.052 .

Table 2. Summary of Normality test For Skewness and Kurtosis of Variables

\begin{tabular}{ccc}
\hline Variables & Skewness & Kurtosis \\
\hline IV-Government Factor & 0.018 & 0.167 \\
IV- Customer Factor & -0.355 & -0.876 \\
IV- Supplier Factor & 0.142 & -0.682 \\
IV- Manager Factor & -0.029 & -0.052 \\
IV-Employee Factor & 0.443 & -0.268 \\
IV-Technology Innovations & 0.133 & -0.156 \\
DV- The Current GWP & 0.102 & -0.190 \\
\hline
\end{tabular}

\subsection{Pearson Correlation Coefficient Test}

Pearson correlation can be defines as an instrument to evaluate the intensity and strength of a linear relationship between two or more variables [25]. It is stated as Pearson's correlation or simply as the correlation coefficient. If the relationship between the variables is not linear, it means that the correlation coefficient does not adequately represent the strength of the connection between the variables. Table 3 shows the summary of Pearson correlation test. Based on Table 3, the p-value of the correlation between two variables is 0.000 which is significant at the 0.01 level of 2 -tailed. This indicates that there is a positive and strong relationship between independent variables and dependent variable. Based on the result, the strength of the relationship between government factor and green warehouse practice is strong $(\mathrm{r}=0.982, \mathrm{r}>0.5)$. It clarified a significant relationship. Besides, the strength of relationship between manager factor and green warehouse practice is
Furthermore, the skewness and kurtosis value on employee factor is 0.443 and -0.268 . The skewness and kurtosis value of technology innovation factor is 0.133 and -0.156. Lastly, the result of the skewness and kurtosis value of dependent variables is 0.102 and -0.190 . All the values are normally distributed which falls within the acceptable range of -1.00 to +1.00 in both skewness and kurtosis.

strong $(\mathrm{r}=0.963, \quad \mathrm{r}>0.5)$. It clarified a significant relationship. Next, the strength of relationship between customer factor and green warehouse practice is strong $(\mathrm{r}=0.730, \mathrm{r}>0.5)$. It clarified a significant relationship. Also, the strength of relationship between supplier factor and green warehouse practice is strong $(\mathrm{r}=0.899, \mathrm{r}>0.5)$. It clarified a significant relationship. Next, the strength of relationship between employee factor and green warehouse practice is strong $(\mathrm{r}=0.589, \mathrm{r}>0.5)$. It clarified a significant relationship. Lastly, the strength of relationship between independent variable of technology innovations factor and green warehouse practice is strong $(\mathrm{r}=0.50, \mathrm{r}>0.5)$. It clarified a significant relationship. From the Table 3 of the correlation results, it could be concluded that IV1 to IV6 has strong relationship with the green warehouse practice in current working environment. The government and managers factors were the most important factor to influence the green warehouse practice where employees and technology innovation were less important influencers.

Table 3. Summary Results Of Pearson Correlation

\begin{tabular}{cc}
\hline Variables & Pearson Correlation \\
\hline Government Factor & 0.982 \\
Customer Factor & 0.730 \\
Supplier Factor & 0.899 \\
Manager Factor & 0.963 \\
Employee Factor & 0.589 \\
Technology innovations Factor & 0.562 \\
\hline
\end{tabular}

\subsection{Analysis of Variances (ANOVA)}

Based on table 4, it showed the output of the ANOVA analysis whether there are statistically significant difference between means. The significant value is 0.000 $(\mathrm{p}=.000)$, which is less than the significance level of 0.05 . Thus, the null hypothesis had been rejected and concluded that some of the regression have different means. There was a statistically significant different between group as determined by one-way ANOVA $(\mathrm{F}(6,166)=927.371, \mathrm{p}=.000 \mathrm{~b})$ 
Table 4. ANOVA result

\begin{tabular}{cccccc}
\hline Model & Sum of squares & df & Mean Square & F & Sig \\
\hline Regression & 69.883 & 6 & 11.647 & 927.371 & $.000^{\mathrm{b}}$ \\
Residual & 2.085 & 166 & .013 & & \\
Total & 71.968 & 172 & & & \\
\hline
\end{tabular}

a. Dependent Variable: DV

b. Predictors: (Constant), IV6, IV1, IV5, IV2, IV3, IV4

\subsection{Regression Analysis}

From the Table 5, it showed that $\mathrm{R}$ value is 0.985 which is very close to 1 . In this research paper, independent variables act as a role to predictor. The dependent variable acts as a role of response which is being predicted by the independent variables. Thus, green warehouse practices can be defined well by all the independent variables: government factor, customer factor, supplier factor, manager factor, employee factor and also IT factor. However, when the $\mathrm{R}$ value is close to 0 , which mean that the green warehouse practices adoption is described by the unknown factors, In addition, the differences between data and regression line can be measured by using $\mathrm{R}$ square value which is 0.971 .

Table 5. Model summary

\begin{tabular}{ccccc}
\hline Model & R & R Square & Adjusted R Square & Std. Error of the Estimate \\
\hline 1 & $.985 \mathrm{a}$ & .971 & .970 & .11207 \\
\hline
\end{tabular}

a. Predictors: (Constant), IV1, IV2, IV3, IV4, IV5, IV6

b. Dependent Variable: DV

Based the Table 6, it showed the $\mathrm{t}$ value for the six independent variables in this research. The $t$ value of government factor is 14.615 , the $t$ value of customer factor is 2.141 and the $t$ value of employee factor is 3.860 . It shows a strong positive relationship with dependent

variables. Moreover, the $t$ value of on supplier factor is 1.889 , the $t$ value of manager factor is -3.787 and the $t$ value of technology innovations factor is -2.343 . Hence, there is strong negative relationship with dependent variables.

Table 6. Coefficients

\begin{tabular}{|c|c|c|c|c|c|}
\hline \multirow[t]{2}{*}{ Model } & \multicolumn{2}{|c|}{ Unstandardized Coefficients } & \multirow{2}{*}{$\begin{array}{l}\text { Standardized } \\
\text { Coefficients }\end{array}$} & \multirow[t]{2}{*}{$\mathbf{t}$} & \multirow[t]{2}{*}{ Sig. } \\
\hline & $\mathbf{B}$ & Std Error & & & \\
\hline 1Constant & -.371 & .053 & & -7.047 & .000 \\
\hline IV1 & 1.464 & .100 & 1.365 & 14.615 & .000 \\
\hline IV2 & .067 & .031 & .064 & 2.141 & .034 \\
\hline IV3 & -.109 & .058 & -.094 & -1.889 & .061 \\
\hline IV4 & -.387 & .102 & -.372 & -3.787 & .000 \\
\hline IV5 & .070 & .018 & .086 & 3.860 & .000 \\
\hline IV6 & -.048 & .021 & -.051 & -2.343 & .020 \\
\hline
\end{tabular}

Thus based on Table 6, the following regression equation is deduced. Y (Green Warehouse Practices) $=$ $\mathrm{X} 1(1.464)+\mathrm{X} 2(0.067)+\mathrm{X} 3(-0.109)+\mathrm{X} 4(-0.387)+$ $\mathrm{X} 5(0.070)+\mathrm{X} 6(-0.048)+\mathrm{C}(-0.371)$. Based on the table above, it shows that if government factor increase one unit in the result, it would increase 1.464 unit for green warehouse practices adoption. In contrast, customer factor increase one unit in result, it would increase 0.067 unit for green warehouse practices adoption.

When employee factor increase one unit in result, it would increase 0.070 unit for green warehouse practices adoption. On the other hand, if supplier factor increase one unit in result, it would decrease 0.019 for green warehouse practices adoption.

When manager factor increase one unit in result, it would decrease 0.387 for adopting green warehouse practices. Moreover, if technology innovations factor increase one unit in result, it would decrease 0.048 for adopting green warehouse practices.
Moreover, the p-value for the six independent variables in this research had been showed in the table above. When the p-value is lower than value of 0.05 , it shows that the predictor independent variables are significant affect the dependent variable.

From the table 6 , it showed that the p-value for customer factor is 0.034 . However, the $p$-value for supplier factor is 0.061 and the p-value of IT factor is 0.020. Then, the $p$-value for of government factor, manager factor and employee factor is 0.000 . Thus, in the result, all of the p-value for independent variables except customer, supplier and technology innovations factor are lower than value of 0.05 that will influence the dependent variables in this research finding.

\subsection{Overall discussion}

Thus overall, based on the analysis done, the following are deduced. Based on the result showed in Pearson Correlation Coefficient Test, the correlation value for government factor is $\mathrm{r}=0.982$ which in between 0.5 to 1.0 . 
Thus, the strength of relationship between government factor and green warehouse practices adoption is strong and positive. Plus, the $\mathrm{p}$-value for government factor is $\mathrm{p}=0.000$ which is lower than 0.05 . Hence, it showed that government factor affect as well as had a relationship with GWP.

In addition, based on the result in regression analysis that analyzed by using SPSS, it demonstrated that the $\mathrm{p}$ value for government factor is $\mathrm{p}=0.000$. It is lower than 0.05 which shows that the government factor is significant affect the dependent variable of GWP adoption. Thus, $\mathrm{H}_{1} 1$ is accepted whereas $\mathrm{H}_{\mathrm{o}} 1$ is rejected.

According to the result showed in Pearson Correlation Coefficient Test, the correlation value for customer factor is $\mathrm{r}=0.730$ that is within the range of 0.5 to 1.0. Thus, there is a strong and positive relationship between customer factor and GWP adoption. Moreover, the $\mathrm{p}$-value for customer factor is $\mathrm{p}=0.000$ which is lower than 0.05 . Hence, it describes that customer factor had a relationship with GWP and will also influence them.

In addition, based on the result in regression analysis that analyzed by using SPSS, the customer factor had a $p$-value of $p=0.034$. The value of 0.034 is lower than the significant level 0.05 . Thus, it shows that customer factor is significant affect to the dependent variable of GWP adoption. It also represents that $\mathrm{H}_{1} 2$ is accepted whereas $\mathrm{H}_{0} 2$ is rejected.

Based on the result showed in Pearson Correlation Coefficient Test, the correlation value for supplier factor is $\mathrm{r}=0.899$ which in between 0.5 to 1.0 . Thus, the strength of relationship between supplier factor and green warehouse practices adoption is strong and positive. And also, the $p$-value for of supplier factor is $\mathrm{p}=0.000$ which is lower than 0.05 . Hence, it shows that supplier factor affect as well as had a relationship with GWP.

In addition, based on the result in regression analysis that analyzed by using SPSS, it demonstrated that the pvalue for supplier factor is $p=0.061$. This value of 0.061 is lower than 0.05 which shows that the supplier factor is significant affects GWP. Thus, $\mathrm{H}_{1} 3$ is accepted whereas $\mathrm{H}_{\mathrm{o}} 3$ is rejected.

Based on the result showed in Pearson Correlation Coefficient Test, the correlation value for manager factor is $r=0.963$ which in between 0.5 to 1.0. Thus, the strength of relationship between manager factor and green warehouse practices is strong and positive. Plus, the $\mathrm{p}$ value for the manager factor is $\mathrm{p}=0.000$ which is lower than 0.05 . Hence, it showed that manager factor had a relationship with GWP adoption.

In addition, based on the result in regression analysis that analyzed by using SPSS, it demonstrated that the $\mathrm{p}$ value for manager factor is $p=0.000$. This value of 0.000 is lower than 0.05 which showed that the manager factor is significant affects the GWP. Thus, $\mathrm{H}_{1} 4$ is accepted whereas $\mathrm{H}_{0} 4$ is rejected.

Based on the result showed in Pearson Correlation Coefficient Test, the correlation value for employee factor is $r=0.589$ which in between 0.5 to 1.0 . Thus, the strength of relationship between employee factor and GWP is strong and positive. And also, the p-value for the internal stakeholder of employee factor is $\mathrm{p}=0.000$ which is lower than 0.05 . Hence, it showed that employee factor had a relationship with GWP.

In addition, based on the result in regression analysis that analyzed by using SPSS, it demonstrated that the pvalue for of employee factor is $p=0.000$. This value of 0.000 is lower than 0.05 which showed that the employee factor significant affects the GWP. Thus, $\mathrm{H}_{1} 5$ is accepted whereas $\mathrm{H}_{0} 5$ is rejected.

Based on the result showed in Pearson Correlation Coefficient Test, the correlation value for technology innovations factor is $\mathrm{r}=0.562$ which in between 0.5 to 1.0 . Thus, the strength of relationship between of technology innovations factor and GWP is strong and positive. And also, the $p$-value for the IT factor is $p=0.000$ which is lower than 0.05 . Hence, it showed that this factor affects had a relationship with GWP.

In addition, based on the result in regression analysis that analyzed by using SPSS, it demonstrated that the pvalue for technology innovation factor is $p=0.020$. This value of 0.020 is lower than 0.05 which shows that the independent variable of technology innovations factor affects significantly the GWP. Thus, $\mathrm{H}_{1} 6$ is accepted whereas $\mathrm{H}_{0} 6$ is rejected.

From the results in the table of Coefficients in regression analysis, the suppliers, managers and technology innovation were a negatively significant variables as they had a $\mathrm{B}=-0.109,-0.387$ and -0.048 respectively whereas government, customers and employee had a $\mathrm{B}=1.464,0.067$ and 0.070 respectively. These three variables were positively significant variables. The negative value indicated there was an inverse relationship between supplier, manager and technology innovation with green warehouse practices.

The supplier has an inversely relationship with the GWP. As the number of green supplier emerged along the supply chain and logistics industry, what they have expected for being green in the operation, would only in term of the transportation and shipping sectors. Since the carbon footprint reduction was significant in those industries involve of vehicle. Hence, the focus would be only stressed on these industry but not the intermediated elements such as warehousing. As Malaysia is a developing country, most of the people living with oldfashion and narrow vision being going green. The extension to the warehouse industry would be neglected more as the demand from green supplier increased in the market. However, the situation could be recover if the customers' requisition on greener warehouse to store their commodity and goods. The customers promote the use of green warehouse would definitely increase the demand in turn increased the number of GWP in the industry as the "green" term is emerged as a competitive advantages in getting more customers. Hence, customers and the GWP has a positive variable relationship with $\mathrm{B}=0.067$.

This could be the reason that managers did not see green practice as a future opportunity to be sustainable in the industry and they were not active to encourage their employees to have green mind set. Besides, they might not think that warehousing industry could help to reduce the carbon footprint as they concern only in the 
transportation part. Managers hold a crucial role in the company, from the results from the coefficient could be seen that the more involvement of manager, the least the GWP. This might be due to, the local employees' view on the term of "green" and "eco". Although the mangers encourage the employees to go green and help them to adopt green initiative during daily activities yet the oldfashion thought that held by the employees are hardly changed. A transformation of type of business across the organization is hard without the participation of all the levels of employees. Hence, the researcher could say that the involvement of employees might contribute more on the decision for the organization to go green. This was indicated by the $\mathrm{B}$ value of the employee factor $(\mathrm{B}=0.007)$.

Furthermore, the more technology innovated did help to promote greener facilities and tools, yet it needed large initial investment before little profit return as it generated in long run competition. The huge investments are only affordable for huge and large-scale company, such as multinational company. From the data collection, both multination and local companies involved evenly. Although the number of respondent from multination company were greater than the local ones, however, they might think that technology innovations were still new emerging option for them to go green in Malaysia as Malaysia remains as developing country. Those hightech innovations might not suitable to fit in the working environment currently but will then get improvement as the time goes. This could be an exception if there was an financial support from the government or regulations that exerted pressure on the implementation of going green in this industry. This was indicated by the B value of 1.464 from the government factor. This could relate to where the financial support from the government would help the organization to get huge capital and finance in order to adopt new technology in their warehouse. The finance from government might become the 'extra' capital in order for the organization to invest in the new facilities and technology such as AS/RS discussed in the literature review.

Finally, with the B-value of 1.464 , the government factor is the most significant variable to indicate the GWP as without the support of government and policy maker, any new and innovated ides could not be implemented.

\section{CONCLUSION}

In this work, the current green warehouse practice (GHP) in Malaysia and the factors affecting them was analyzed. The relationship between government engagement, customer, supplier, manager, employee's engagement, technology innovation and green warehouse practice has been studied. The outcome of this work showed that all independent variable had a strong relationship with the green warehouse practice in current working environment. The government and managers factors were the most important factor to influence the green warehouse practice. This research has provided details information with regards to how the warehousing industry interprets the effect on negative environmental significances.

\section{References}

1. Saad, R., Rahim, S. A., \& Fernando, Y. (2016). Sustainable green supply chain management and impact on organisations. Journal of Emerging Trends in Economics and Management Sciences, 7(3), 147-155.

2. Xia, Y., \& Wang, B. (2013). Green Logistics in Logistics Industry in Finland. Bachelor Thesis, Lahti University of Applied Sciences, Finland.

3. Laari, S., Töyli, J., \& Ojala, L. (2017). Supply chain perspective on competitive strategies and green supply chain management strategies. Journal of cleaner production, 141, 1303-1315.

4. Evangelista, P. (2014). Environmental sustainability practices in the transport and logistics service industry: An exploratory case study investigation. Research in Transportation Business \& Management, 12, 63-72.

5. Amjed, T. W., \& Harrison, N. J. (2013). A Model for sustainable warehousing: from theory to best practices. In Proceedings of the International Decision Sciences Institute and Asia Pacific DSI Conference.

6. Richards, G. (2017). Warehouse management: a complete guide to improving efficiency and minimizing costs in the modern warehouse. Kogan Page Publishers.

7. Accorsi, R., Bortolini, M., Gamberi, M., Manzini, R., \& Pilati, F. (2017). Multi-objective warehouse building design to optimize the cycle time, total cost and carbon footprint. The International Journal of Advanced Manufacturing Technology, 92(1-4), 839854.

8. Piecyk, M., Browne, M., Whiteing, A., \& McKinnon, A. (Eds.). (2015). Green logistics: Improving the environmental sustainability of logistics. Kogan Page Publishers.

9. Rao, P. H. (2014). Measuring environmental performance across a green supply chain: a managerial overview of environmental indicators. Vikalpa, 39(1), 57-74.

10. Ho, J. C., Shalishali, M. K., Tseng, T., \& Ang, D. S. (2009). Opportunities in green supply chain management. The Coastal Business Journal, 8(1), 18-31.

11. Sharma, V. K., Chandna, P., \& Bhardwaj, A. (2017) Green supply chain management related performance indicators in agro industry: A review. Journal of Cleaner Production, 141, 11941208.

12. Miranda-Ackerman, M. A., Azzaro-Pantel, C., \& Aguilar-Lasserre, A. A. (2017). A green supply chain network design framework for the processed food industry: Application to the orange juice agrofood cluster. Computers \& Industrial Engineering, 109, 369-389.

13. Chen, Y. S., Chang, C. H., \& Wu, F. S. (2012). 
Origins of green innovations: the differences between proactive and reactive green innovations. Management Decision, 50(3), 368-398.

14. Ahi, P., \& Searcy, C. (2013). A comparative literature analysis of definitions for green and sustainable supply chain management. Journal of cleaner production, 52, 329-341.

15. Seroka-Stolka, O. (2014). The development of green logistics for implementation sustainable development strategy in companies. ProcediaSocial and Behavioral Sciences, 151, 302-309.

16. Govindan, K., Rajendran, S., Sarkis, J., \& Murugesan, P. (2015). Multi criteria decision making approaches for green supplier evaluation and selection: a literature review. Journal of Cleaner Production, 98, 66-83.

17. Lee, V. H., Ooi, K. B., Chong, A. Y. L., \& Seow, C. (2014). Creating technological innovation via green supply chain management: An empirical analysis. Expert Systems with Applications, 41(16), 6983-6994.

18. Chen, X., Wang, X., Kumar, V., \& Kumar, N. (2016). Low carbon warehouse management under cap-and-trade policy. Journal of cleaner production, 139, 894-904.

19. Rüdiger, D., Schön, A., \& Dobers, K. (2016). Managing greenhouse gas emissions from warehousing and transshipment with environmental performance indicators. Transportation Research
Procedia, 14, 886-895.

20. Sham, R., Wahab S.N., \& Hussin, A.A.A. (2018). Smart Trolley Apps: A Solution to Reduce Picking Error. International Journal of Supply Chain Management, 7(5), 294-302.

21. Rajendran, S.D., and Wahab, S.N. (2017) Purchasing Intention towards Green Packaged Products: An Exploratory Study among Malaysian Consumers, 3rd International Conference on Advanced Research in Business and Social Sciences, 29-30 March, 347-355, Langkawi Malaysia.

22. Ayuso, S., Ángel Rodríguez, M., García-Castro, R., \& Ángel Ariño, M. (2011). Does stakeholder engagement promote sustainable innovation orientation?. Industrial Management \& Data Systems, 111(9), 1399-1417.

23. Teo, A. C., Tan, G. W. H., Ooi, K. B., Hew, T. S., \& Yew, K. T. (2015). The effects of convenience and speed in m-payment. Industrial Management \& Data Systems, 115(2), 311-331.

24. Rajendran, S.D., Wahab, S.N, Ling, Y.W., and Yun, L.S. (2018). The Impact of Logistics Services On the E-Shoppers' Satisfaction, International Journal of Supply Chain Management, 7(5), 461-469.

25. Tunstall, Samuel L. (2016). Open Access!: Review of Online Statistics: An Interactive Multimedia Course of Study by David Lane. Numeracy 9, Iss. 1: Article 9. DOI: http://dx.doi.org/10.5038/19364660.9.1.9 